\title{
Tackling Epidemic of Obesity: Are We Fighting a Losing Battle?
}

\author{
Surinder S Rana
}

Journal of Postgraduate Medicine, Education and Research (2021): 10.5005/jp-journals-10028-1424

Obesity is an epidemic that has reached alarming proportions both in the developed as well as developing countries and is a known risk factor for a number of chronic noncommunicable diseases like diabetes, hypertension, coronary artery diseases, liver diseases, joint diseases, sleep apnea, and a number of cancers. ${ }^{1}$ Recent pandemic of coronavirus disease-2019 (COVID-19) has put back the focus on the epidemic of obesity. Studies have shown that the high body mass index (BMI) is associated with increased hospitalization, the need for mechanical ventilation, and mortality in patients with COVID-19. 2,3 An alarming trend of increased prevalence of obesity is not only being witnessed in adults but also in children and thus has led on to increased prevalence of noncommunicable diseases like diabetes and hypertension in children. ${ }^{4}$ Obesity has not only disastrous physiological and metabolic consequences but also results in important psychosocial consequences. The primary cause for obesity is an increased calorie intake along with a sedentary lifestyle and the modern lifestyle promotes both these factors.

Combating obesity requires a persistent and multifaceted, structured, and comprehensive multispecialty approach for its prevention and treatment. The management of obesity involves nonpharmacological approaches like lifestyle modification with decreased calories intake and increased physical activity and interventional approaches including drugs and surgery. The aim of treatment of obesity is to prevent, treat, and, if possible, reverse the complications associated with obesity and improve the quality of life. Currently, the management options are offered according to the BMI and presence of obesity-related comorbidities. Patients with $\mathrm{BMI}>30 \mathrm{~kg} / \mathrm{m}^{2}$ or $\mathrm{BMI}>27 \mathrm{~kg} / \mathrm{m}^{2}$ with comorbidities are usually treated with drugs along with lifestyle modification whereas patients with $\mathrm{BMI}>40 \mathrm{~kg} / \mathrm{m}^{2}$ or $\mathrm{BMI}>35 \mathrm{~kg} / \mathrm{m}^{2}$ with multiple obesity-related complications are offered surgery. ${ }^{5,6}$ Currently, bariatric surgery is considered as the most effective modality for long-term weight loss in patients with obesity but perceived fear of surgery as well as risk of complications has resulted in its limited adoption in patients. ${ }^{7}$ Advent of novel minimally invasive endoscopic therapies for obesity has ushered a new era for effective nonsurgical endoscopic bariatric treatment of obesity. These minimally invasive procedures with minimal complications and quick recovery time have potential to be a gamechanger in the management of obesity.

In this issue of JPMER, we have leading national as well as international experts discussing various aspects of obesity and
Departments of Gastroenterology, Postgraduate Institute of Medical Education and Research, Chandigarh, India

Corresponding Author: Surinder S Rana, Department of Gastroenterology, Postgraduate Institute of Medical Education and Research, Chandigarh, India, Phone: +91-172-2756555, e-mail: drsurinderrana@gmail.com

How to cite this article: Rana SS. Tackling Epidemic of Obesity: Are We Fighting a Losing Battle? J Postgrad Med Edu Res 2021;55(1):1.

Source of support: Nil

Conflict of interest: None

its management including cardiovascular, liver, pancreatic and orthopedic consequences along with surgical as well as recent endoscopic management techniques. The important topic of pediatric obesity and its consequences has also been discussed in detail. I am sure the readers will find these articles informative and get updated on recent advances in the management of obesity. It is important for us to realize the serious consequences of obesity and demonstrate urgency in responding to this exploding epidemic before it is too late!

\section{References}

1. Chopra S, Malhotra A, Ranjan P, et al. Lifestyle-related advice in the management of obesity: a step-wise approach. J Educ Health Promot 2020;9(1):239. DOI: 10.4103/jehp.jehp_216_20.

2. Albashir AAD. The potential impacts of obesity on COVID-19. Clin Med (Lond) 2020;20(4):e109-e113. DOI: 10.7861/clinmed.2020-0239.

3. Rebello CJ, Kirwan JP, Greenway FL. Obesity, the most common comorbidity in SARS-CoV-2: is leptin the link? Int J Obes (Lond) 2020;44(9):1810-1817. DOI: 10.1038/s41366-020-0640-5.

4. Wieting JM. Cause and effect in childhood obesity: solutions for a national epidemic. J Am Osteopath Assoc 2008;108(10):545-552.

5. Apovian CM, Aronne LJ, Bessesen DH, et al. Endocrine society. Pharmacological management of obesity: an endocrine society clinical practice guideline. J Clin Endocrinol Metab 2015;100(2):342362. DOI: $10.1210 /$ jc.2014-3415.

6. Montesi L, El Ghoch M, Brodosi L, et al. Long-term weight loss maintenance for obesity: a multidisciplinary approach. Diabetes Metab Syndr Obes 2016;9:37-46. DOI: 10.2147/DMSO.S89836.

7. Farha J, Abbarh S, Haq Z, et al. Endobariatrics and metabolic endoscopy: can we solve the obesity epidemic with our scope? Curr Gastroenterol Rep 2020;22(12):60. DOI: 10.1007/s11894-020-00798-8.

\footnotetext{
(c) The Author(s). 2021 Open Access This article is distributed under the terms of the Creative Commons Attribution 4.0 International License (https:// creativecommons.org/licenses/by-nc/4.0/), which permits unrestricted use, distribution, and non-commercial reproduction in any medium, provided you give appropriate credit to the original author(s) and the source, provide a link to the Creative Commons license, and indicate if changes were made. The Creative Commons Public Domain Dedication waiver (http://creativecommons.org/publicdomain/zero/1.0/) applies to the data made available in this article, unless otherwise stated.
} 